\title{
Detection of Acid Fast Bacilli in Tuberculous Lymph Node Tissue and Touch Preparations-A Comparative Study
}

\author{
Ghulam Rasool', Muhammad Rashid Siraj', Nadia Naseem¹, Sameer Anjum¹, Waqas Lateef', \\ A. H. Nagi ${ }^{1}$
}

${ }^{1}$ Department of Morbid Anatomy \& Histopathology, University of Health Sciences, Lahore, Pakistan

${ }^{2}$ Department of Surgery, Akhtar Saeed Medical \& Dental College, Lahore, Pakistan

Email: g.rasool18@hotmail.com

How to cite this paper: Rasool, G., Siraj, M.R., Naseem, N., Anjum, S., Lateef, W. and Nagi, A.H. (2017) Detection of Acid Fast Bacilli in Tuberculous Lymph Node Tissue and Touch Preparations-A Comparative Study. Journal of Tuberculosis Research, 5, 168-177.

https://doi.org/10.4236/jtr.2017.53019

Received: June 13, 2017

Accepted: August 20, 2017

Published: August 23, 2017

Copyright $\odot 2017$ by authors and Scientific Research Publishing Inc. This work is licensed under the Creative Commons Attribution International License (CC BY 4.0).

http://creativecommons.org/licenses/by/4.0/

\begin{abstract}
Background: The most common form of extrapulmonary tuberculosis is lymphadenitis. Lymphadenitis is considered mainly a disease of young children and has a peak age of onset at 20 to 40 years. Objectives: The purpose of this study was to detect and compare the presence of acid fast bacilli in lymph node biopsies and their touch preparations using Ziehl Neelsen and fluorescence staining. Materials and Methods: The lymph node biopsies and their touch preparations were prepared and stained with Haematoxylin and eosin to determine their morphology. Slides were stained with $\mathrm{ZN}$ staining and fluorescent staining technique using Auramine $\mathrm{O}$ and Rohdamine B to demonstrate the presence of acid fast bacilli in tissue and their touch preparations. Results: AFB was detected in $56 \%$ of biopsies and $54 \%$ of touch preparations. In addition in these cases we observed that fluorescent staining technique using Auramine $\mathrm{O}$ and Rohdamine B is superior to $\mathrm{ZN}$ stain because low magnification used in fluorescent staining technique makes it possible to scan the smear rapidly and detects the AFB as glowing spots even if it is present in small numbers. Conclusion: The results of AFB in tissue biopsies are in equivalent in their touch preparation.
\end{abstract}

\section{Keywords}

Haematoxylin and Eosin, Acid Fast Bacilli, Touch Preparation

\section{Introduction}

The most common form of extrapulmonary tuberculosis is lymphadenitis. Among those cervical lymphadenopathy is most frequent, but inguinal, axillary, 
mesenteric, mediastinal and intramammary involvement is also noticed in many cases [1]. Lymphadenitis is a disease of children and young adults and has a peak age of onset of 20 to 40 years. In United States it is most frequent in women and immigrants. The lymph nodes are discrete, firm and nontender but with passage of time a firm mass of matted nodes are easily seen. If anti tuberculosis treatment is not given to the patient, the lymph node becomes fluctuant and drain spontaneously with sinus tract formation [2]. Mostly patients have positive tuberculin skin test and chest radiography results are also normal. Excisional biopsy of lymph nodes with history and histology and acid fast bacilli stains and mycobacterial cultures are the diagnostic procedure of choice [3] [4]. The use of fine needle aspiration technique in the patients with tuberculous lymphadenitis is highly variable. Fine needle aspiration is better technique because of higher mycobacterial burden. Polymerase chain reaction (PCR) for Mycobacterium tuberculosis using fine needle aspiration specimens, increases the test sensitivity [2].

Most samples that are submitted for acid-fast bacilli (AFB) testing are collected because the health practitioner suspects that a person has tuberculosis (TB), caused by Mycobacterium tuberculosis. Mycobacteria are called acid-fast bacilli because they are a group of rod-shaped bacteria (bacilli) that can be seen under the microscope following a staining procedure where the bacteria retain the color of the stain after an acid wash (acid-fast). AFB laboratory tests detect the bacteria in a person's sample and help identify an infection caused by AFB [5]. The high content of mycolic acid in the cell wall of mycobacteria is main reason for the staining pattern of poor absorption followed by high retention. The most frequent staining procedure used to detect the presence of AFB is Ziehl-Neelsen (ZN) staining. This technique was introduced by Ziehl-Neelsen in year 1882-1883. In this staining technique acid fast bacilli take bright red colour and background is blue. Another staining technique called Kinyoun method is also used for acid fast bacilli (AFB) identification in which AFB take bright red colour and background is blue green. Acid fast bacteria can also be identified by using fluorescence microscopy using special fluorescent dyes such as auraminerhodamine and auramine-phenol [6].

The conventional detection techniques for tuberculosis are based on microscopy from sputum smear to see AFB. It is the simplest and conventional detection method and has been used in its diagnosis for the past 100 years [7]. The sensitivity of AFB in sputum smear is only $50 \%-60 \%$ in those laboratories which are well equipped and have staff with skilled technicians, partly because a positive smear requires 5000 - 10,000 AFB per $\mu$ l of sputum sample. Ziehl-Neelsen stain diagnoses the cases that are epidemiologically most significant, i.e., those which are most likely to transfer the disease to those who are in close contacts [8].

Mycobacterium tuberculosis detection staining technique by fluorescence microscopy is about $10 \%$ more sensitive than the Ziehl-Neelsen staining technique and has similar specificity. However fluorescence staining technically is more cost effective and complicated [9]. 


\section{Materials and Methods}

A total of 50 cases with strong clinical suspicion of lymph node tuberculosis were included. Patients with recurrence of TB or patients on antituberculosis treatment were excluded. From the lymph nodes, touch preparations were made and slides were immediately fixed in 70\% ethanol and the lymph node tissue biopsies were also immediately fixed in 10\% formalin (Figure 1 and Figure 2). Later these were sent to the department of Morbid Anatomy and Histopathology at the University of Health Sciences, Lahore, Pakistan where these cases were diagnosed and confirmed for presence tuberculosis.

Then the tissue was processed by automatic tissue processor Microm $\mathrm{GmbH}$ cat. No." 813150 " using different reagents (10\% formalin, ethanol, xylene and paraffin wax). After this tissue is embedded in automatic Tissue Tek TEC model "TEC 5 EMJ-2" using molten paraffin wax. Paraffin embedded sections were prepared using microtome model "RM 2125 RT". The H \& E stain was performed on the slides to determine the histological diagnosis for selecting tissues and only the caseous or non-caseous granulomatous lymph nodes were selected (Figure 3). Slides were stained with ZN staining and fluorescent staining tech-

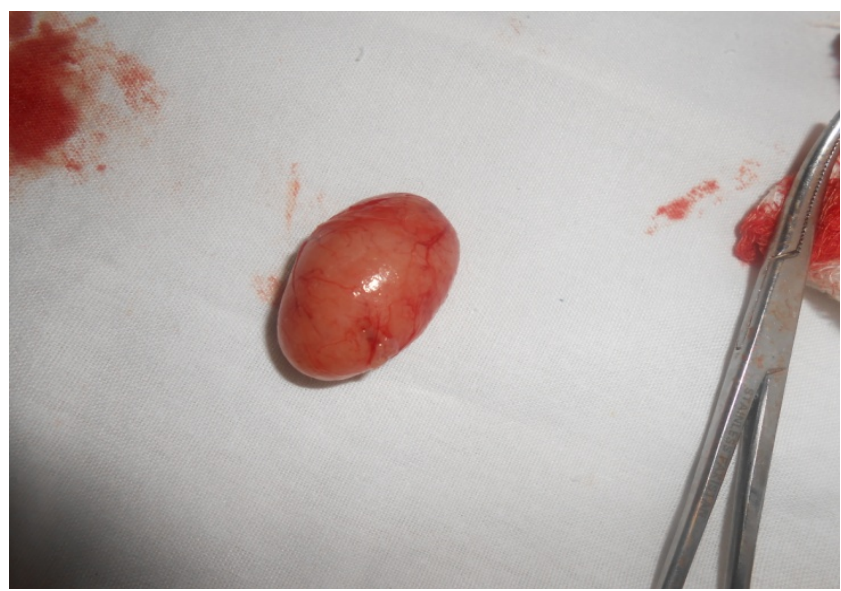

Figure 1. Gross appearance of lymph node showing.

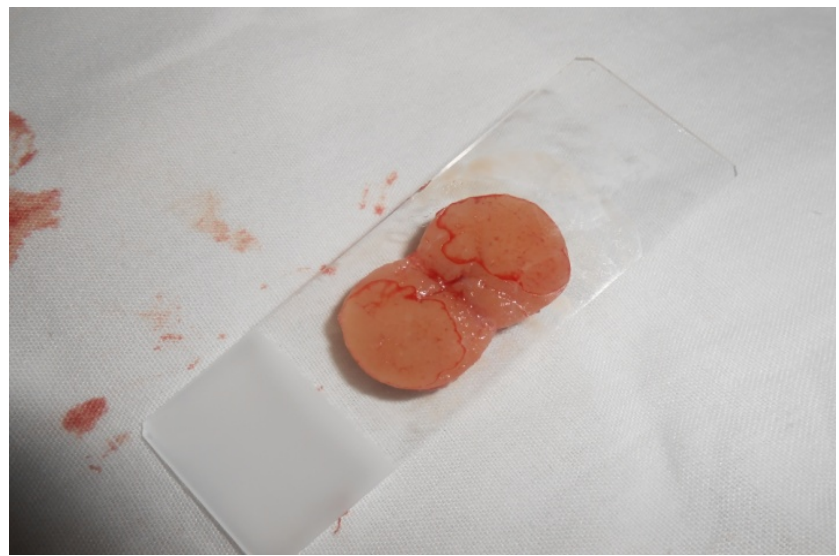

Figure 2. Touch preparation from lymph node caseous necrosis. 


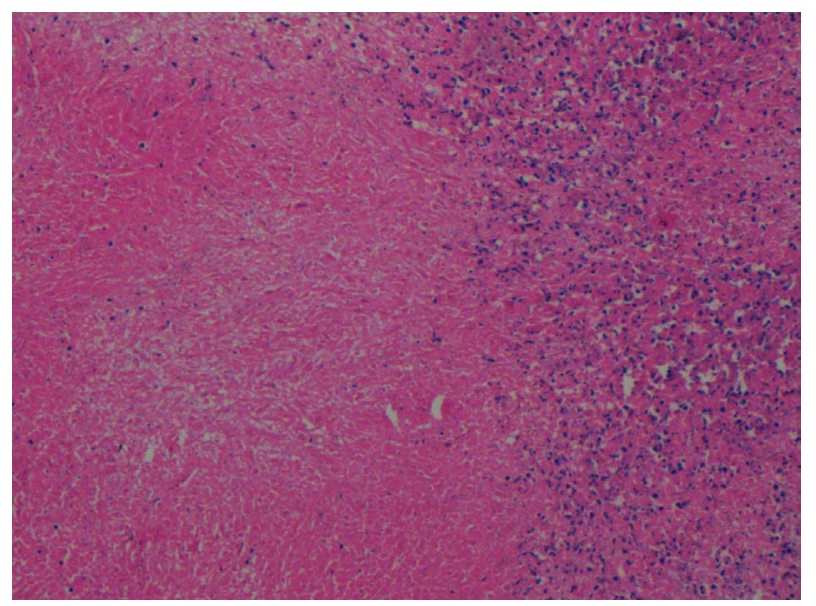

Figure 3. Photomicrograph of lymph node showing extensive early coagulative necrotic changes, $100 \times, \mathrm{H} \& \mathrm{E}$ stain.

nique using Auramine $\mathrm{O}$ and Rhodamine $\mathrm{B}$ to demonstrate the acid fast bacilli in tissue.

Touch preparations slides were also stained with $\mathrm{H}$ \& E stain and then $\mathrm{ZN}$ staining and fluorescent staining technique using Auramine $\mathrm{O}$ and Rhodamine $\mathrm{B}$ to demonstrate the acid fast bacilli in tissue.

Here is a brief account for acid fast bacilli stains summarised along with their characteristics. Results of $\mathrm{ZN}$ stain are such as, AFB are red and backgroud is blue. Results of fluorescence staining technique using Auramine $\mathrm{O}$ and Rohdamine B are similar to AFB but are green (using fluorescence $530 \mathrm{~nm}$ ) and the background is black.

\section{Statistical Analysis}

The data was entered and analysed using SPSS 20. Mean and standard deviation was given for quantitative variables (e.g. age), and the frequencies along with percentages were given for qualitative variables (like gender, detection of $A F B$ on $\mathrm{ZN}$ staining and fluorescence staining). Statistical tests were applied. A p-value of $\leq 0.05$ was regarded as statistically significant. The Sensitivity and Specificity were calculated by using the following formulas: Sensitivity: A/(A + C) $\times 100$-Specificity: $\mathrm{D} /(\mathrm{D}+\mathrm{B}) \times 100[10]$.

\section{Results}

In this study $\mathrm{n}=50$ tuberculous lymph nodes and their touch preparation were included. Cases included 19 (38\%) males and 31 (62\%) females. The study showed that more females were involved than males. Regarding the age distribution of study participants, 12 (24\%) cases of the study subjects were from age of 1 year to 15 years, 25 (50\%) cases of the study subjects were from age 16 to 30 years, $10(20 \%)$ cases of the study subjects were from age 31 to 45 years, 03 (6.0\%) cases of the study subjects were from age 46 to 75 years. The age and gender distribution is given in Table 1. 
Table 1. Frequency distribution of granulomas w.r.t gender, age and lymph node sites.

\begin{tabular}{|c|c|c|c|c|}
\hline & Description & $\begin{array}{c}\text { Necrotizing } \\
\text { granulomas } \\
27(54 \%)\end{array}$ & $\begin{array}{c}\text { Non-necrotizing } \\
\text { granulomas } \\
23(46 \%)\end{array}$ & $\begin{array}{c}\text { Total LN } \\
(50)\end{array}$ \\
\hline & Male & $11(22 \%)$ & $8(16 \%)$ & $19(38 \%)$ \\
\hline \multirow[t]{3}{*}{ Gender } & Female & $24(48 \%)$ & $7(14 \%)$ & $31(62 \%)$ \\
\hline & $01-15$ & $8(16 \%)$ & $4(8 \%)$ & $12(24 \%)$ \\
\hline & $16-30$ & $18(36 \%)$ & $07(14 \%)$ & $25(50 \%)$ \\
\hline \multirow[t]{3}{*}{ Age (Years) } & $31-45$ & $7(14 \%)$ & $3(6 \%)$ & $10(20 \%)$ \\
\hline & $46-75$ & $03(6 \%)$ & $0(0 \%)$ & $03(06 \%)$ \\
\hline & $<1$ & $21(42 \%)$ & $17(34 \%)$ & $38(76 \%)$ \\
\hline \multirow{3}{*}{$\begin{array}{l}\text { Duration of illness } \\
\text { History (Years) }\end{array}$} & $1-2$ & $6(12 \%)$ & $4(8 \%)$ & $10(20 \%)$ \\
\hline & $>3$ & $2(4 \%)$ & $0(0 \%)$ & $02(04 \%)$ \\
\hline & Supraclavicular & $07(14 \%)$ & $5(10 \%)$ & $12(24 \%)$ \\
\hline \multirow{3}{*}{ Lymph Node Site } & Cervical & $23(46 \%)$ & $10(20 \%)$ & $33(66 \%)$ \\
\hline & Axillary & $3(6 \%)$ & $1(2 \%)$ & $4(8 \%)$ \\
\hline & Submandibular & $1(2 \%)$ & $0(0 \%)$ & $1(2 \%)$ \\
\hline \multirow{3}{*}{$\begin{array}{l}\text { Laterality of Lymph } \\
\text { node site }\end{array}$} & Left & $19(38 \%)$ & $14(28 \%)$ & $33(66 \%)$ \\
\hline & Right & $9(18 \%)$ & $8(16 \%)$ & $17(34 \%)$ \\
\hline & Poor & $30(60 \%)$ & $11(22 \%)$ & $41(82 \%)$ \\
\hline \multirow[t]{2}{*}{$\begin{array}{c}\text { Socioeconomic } \\
\text { Status }\end{array}$} & Middle & $6(12 \%)$ & $3(6 \%)$ & $9(18 \%)$ \\
\hline & Upper & $0(0 \%)$ & $0(0 \%)$ & $0(0 \%)$ \\
\hline
\end{tabular}

The study showed that mostly age of patients involved is from 16 to 30 years with a mean age of $15 \pm 12.5$. Regarding the history of the patients, most of the patients presented with a history of fever, cough and lymph node enlargement. The duration of illness varied from 02 months to 3 years with a mean duration of $19 \pm 17.9$ months (Table 1 ).

Lymph nodes were collected from different sites and the site from which these lymph nodes were collected were supraclavicular $(12,24 \%)$, cervical $(33,66 \%)$, axillary $(4,8 \%)$ and submandibular lymph nodes (2.0\%) were included (Table 1$)$.

Final selection of these cases was made by reviewing the $\mathrm{H} \& \mathrm{E}$ staining and all 50 cases showed granulomatous inflammation comprising of both necrotizing (54\%) and non necrotizing granuloma (46\%) (Table 1).

In the 50 cases of tissues and their touch preparations, AFB was microscopically confirmed in 27 cases of tissues and negative in 23 cases and in the touch preparations of these cases 24 were positive and 26 were negative. Fluorescent staining technique using Auramine $\mathrm{O}$ and Rhodamine B for AFB was positive in 28 cases of tissues and negative in 22 cases and in the touch preparations of these cases 27 were positive and 23 were negative (Table 2).

No statically significant association was observed between gender, age and lymph node sites between two groups ( $\mathrm{p}>0.05)$. 
Table 2. This table shows different frequencies of positive AFB as stained by $\mathrm{ZN}$ and Flourescent staining in tissue and touch preparations.

\begin{tabular}{ccccc}
\hline Stain & \multicolumn{2}{c}{50 Tissue Blocks } & \multicolumn{2}{c}{50 Touch Preparations } \\
\hline & Positive & Negative & Positive & Negative \\
Zn & 27 & 23 & 24 & 26 \\
Flourescent Stain & 28 & 22 & 27 & 23 \\
\hline
\end{tabular}

By applying Wilson score, the sensitivity, specificity, positive predictive value, negative predictive value and diagnostic accuracy of Z-N and fluorescent staining were 71.94 vs $87.54,85.69$ vs $79.01,86.2$ vs $82.29,71.0$ vs 85.13 and 83.78 vs 89.5 respectively (Table 3 ).

This depicts better staining outcomes with fluorescent staining in both tissue and touch preparations. However this comparison was not statically significant (p-value $=0.8407$, Chi square) .

By applying Wilson score, the detection of AFB on touch preparations demonstrated $88.89 \%$ sensitivity, $100 \%$ specificity and positive predictive value, $88.46 \%$ negative predictive value and $94 \%$ diagnostic accuracy as compare to tissue analysis, taken as gold standard. However this comparison was not statically significant ( $\mathrm{p}$-value $=0.584$, Chi square) were positive in $45(46 \%)$ cases (Table 4$)$.

\section{Discussion}

This study compared AFB detection in ZN and fluorescent staining in tissue and touch preparations of lymph node samples suspected of tuberculous infection for the first time in Pakistan.

ZN stain was frequently used by various workers [11] [13]. Study conducted by Krishnaswammi and Job in 1972 on tissue sections shows 91 (71.1\%) positive for AFB after ZN staining among 128 lymph nodes having tuberculous lymphadenitis [14]. Study conducted by Greenwood and Fox in 1973 shows 33 (47.1\%) positive for $\mathrm{AFB}$ on $\mathrm{ZN}$ staining technique out of 70 tuberculosis histology cases [15]. Study conducted by Eshete and others in 2011 shows 37 (61.7\%) positive for AFB after ZN staining technique in 60 lymph nodes with tuberculous histology [16]. Study conducted by Rasool et al., in 2017 shows $52.58 \%$ positive for AFB after routine $\mathrm{ZN}$ stain [17]. Our study has revealed 54\% positive for AFB after $\mathrm{ZN}$ stain in tissue biopsy and their touch preparations shows $48 \%$ positive for AFB after ZN staining (Figures 4-6).

Study conducted by Krishnaswammi and Job in 1972 reported 102 (79.7\%) sections positive for AFB on fluorescent technique, out of 128 lymph nodes with tuberculous histology. They used the Kuper and May (1960) method by using Auramine O and Rhodamine B [14]. Study conducted by Greenwood and Fox in 1973 shows 42 (60.0\%) positive for AFB on fluorescent technique, out of 70 tuberculosis histology cases [15]. They applied the Mansfield (1970) method by using Auramine O and phenol. Study conducted by Rasool et al., in 2017 shows 54 (55.67\%) positive for AFB fluorescent staining technique using Auramine O 
Table 3. Single table analysis Z-N stain and fluorescent stain.

\begin{tabular}{ccccc}
\hline & & \multicolumn{3}{c}{ Z-N stain } \\
\cline { 3 - 5 } Fluorescent Stain & Positive & Negative & Total \\
\cline { 3 - 5 } & Positive & 27 & 1 & 28 \\
& Negative & 0 & 22 & 22 \\
& Total & 27 & 23 & 50 \\
\hline
\end{tabular}

Table 4. Single table analysis tissue biopsy and touch preparations.

\begin{tabular}{ccccc}
\hline & & \multicolumn{3}{c}{ Tissue Biopsy } \\
\cline { 3 - 4 } Touch & & Positive & Negative & Total \\
\cline { 2 - 4 } preparations & Positive & 24 & 0 & 24 \\
& Negative & 3 & 23 & 26 \\
& Total & 27 & 23 & 50 \\
\hline
\end{tabular}

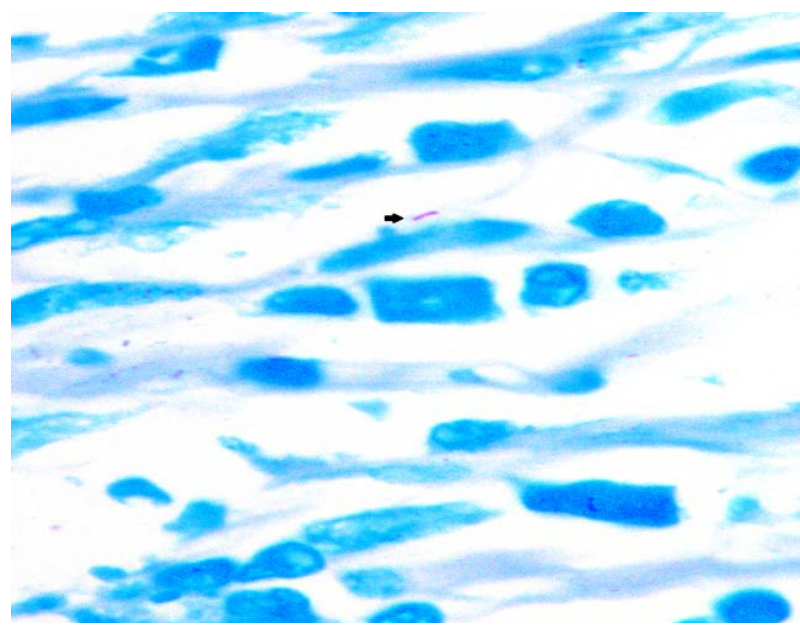

Figure 4. Photomicrograph of lymph node showing AFB in ZN stain, $1000 \times$.

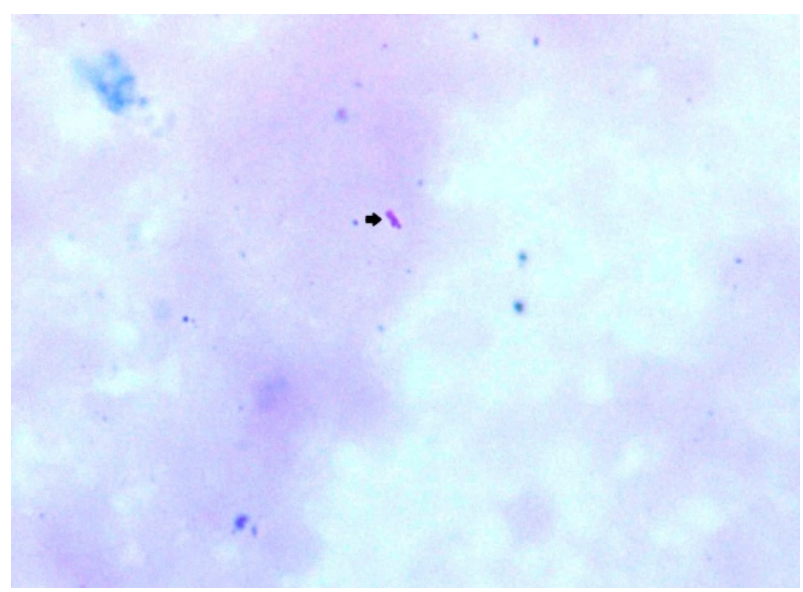

Figure 5. Touch preparation from lymph node showing AFB in $\mathrm{ZN}$ stain, $1000 \times$. 
and Rhodamine B [17]. Our study has revealed 56\% positive for AFB after fluorescent staining in tissue biopsy and their touch preparations shows $54 \%$ positive for AFB after fluorescent staining (Figure 7 and Figure 8). This study shows

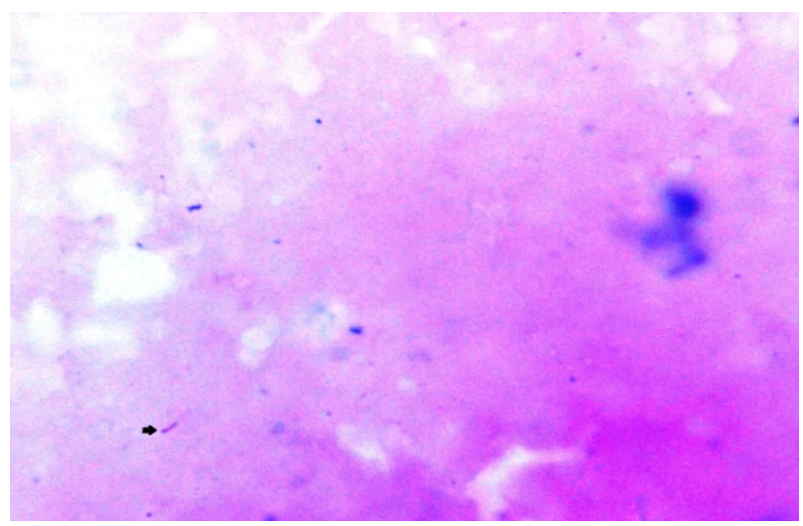

Figure 6. Touch preparation from lymph node showing AFB in $\mathrm{ZN}$ stain, $1000 \times$.

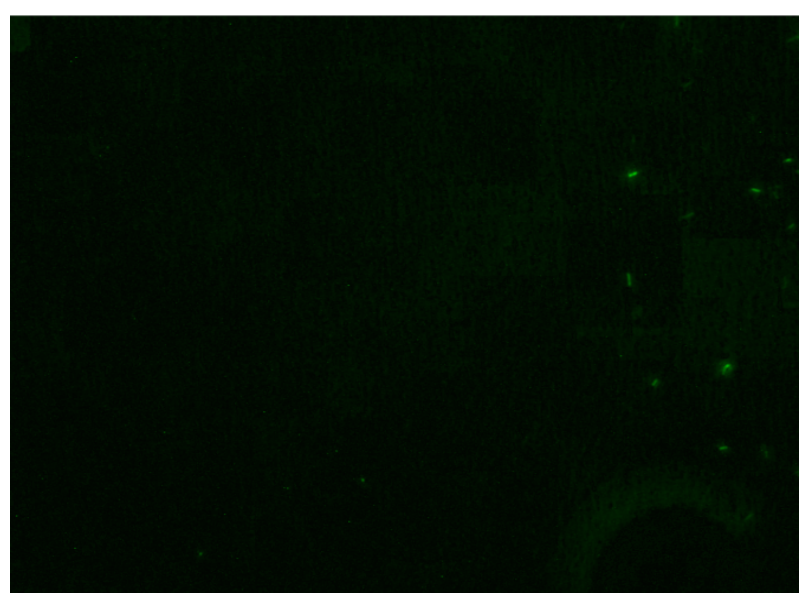

Figure 7. AFB in fluorescent stain Auramine O fluorescent stain using Auramine $\mathrm{O}$ and Rhodamine B, 200×.

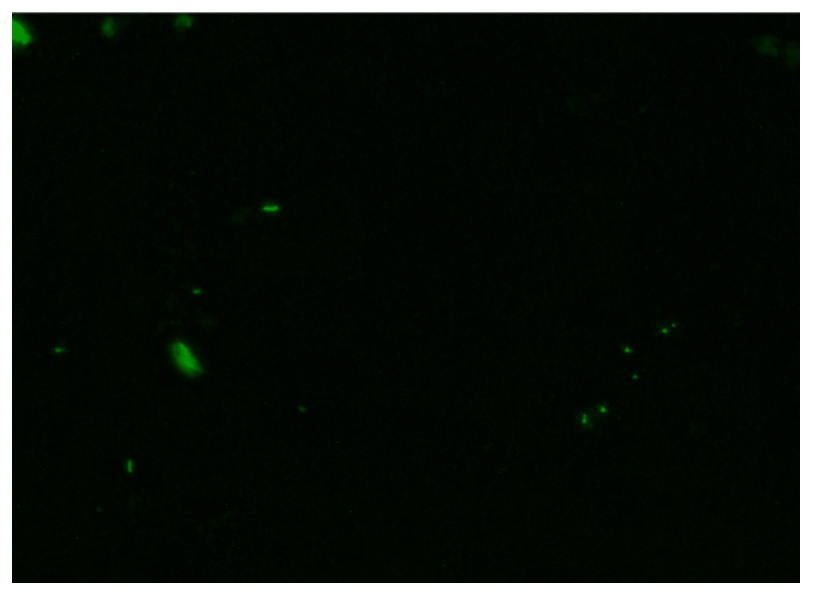

Figure 8. AFB in rod, fragments and beads in and Rhodamine B, $200 \times$. 
that both tissue biopsy and touch preparations have all most equivalent AFB and the results of touch preparation for AFB could be seen urgently as compared to the tissue results.

Our study is comparable with the study of Rasool et al., 2017, Krishnaswammi and Job in 1972, Greenwood and Fox in 1973 and Eshete and others in 2011. Hence our results are comparable to other relevant studies reported worldwide [14] [15] [16] [17].

\section{Conclusions}

AFB detection by fluorescent staining technique is superior to $\mathrm{ZN}$ stain.

Sections negative for acid fast bacilli on ZN stain should be stained with fluorescent stain.

* Touch preparation of the tissue must be prepared in the operation theater because these have comparable sensitivity and specificity as compared to the tissue sections. Also the touch preparations are more rapid and cost-effective method for detection of AFB.

\section{Acknowledgements}

This experiment was supported by University of Health Sciences, Lahore, Pakistan. We are thankful to the staff of clinical and pathology department of Gulab Devi Chest Hospital, Lahore, Pakistan for their sampling and logistic support.

\section{Conflict of Interest}

There are no conflicts of interests regarding this manuscript.

\section{References}

[1] Mert, A., Tabak, F., Ozaras, R., Tahan, V., Öztürk, R. and Aktuglu, Y. (2002) Tuberculous Lymphadenopathy in Adults: A Review of 35 Cases. Acta Chirurgica Belgica, 102, 118-121. https://doi.org/10.1080/00015458.2002.11679277

[2] Artenstein, A.W., Kim, J.H., Williams, W.J. and Chung, R.C. (1995) Isolated Peripheral Tuberculous Lymphadenitis in Adults: Current Clinical and Diagnostic Issues. Clinical Infectious Diseases, 20, 876-882. https://doi.org/10.1093/clinids/20.4.876

[3] American Thoracic Society (2000) Diagnostic Standards and Classification of Tuberculosis in Adults and Children. American Journal of Respiratory and Critical Care Medicine, 161, 1376-1395. https://doi.org/10.1164/ajrccm.161.4.16141

[4] Centers for Disease Control and Prevention (12 September 2006) 2005 Surveillance Slide Set. http://www.cdc.gov/nchstp/tb/pubs/slidesets/surv/surv2005/default.htm

[5] Lab Test Online. https://labtestsonline.org/understanding/analytes/afb-culture/tab/sample/

[6] Chiyoji, A.B. (2003) Standardization of Laboratory Tests for Tuberculosis and Their Proficiency Testing. Kekkaku (Tuberculosis), 78, 541-551.

[7] Reid, M.J. and Shah, N.S. (2009) Approaches to Tuberculosis Screening and Diagnosis in People with HIV in Resource-Limited Settings. The Lancet Infectious Diseases, 9, 173-184. https://doi.org/10.1016/S1473-3099(09)70043-X 
[8] Charles, M. and Pape, J.W. (2006) Tuberculosis and HIV: Implications in the Developing World. Current HIV/AIDS Reports, 3, 139-144. https://doi.org/10.1007/BF02696658

[9] Steingart, K.R., Henry, M., Ng, V., Hopewell, P.C., Ramsay, A., Cunningham, J., Urbanczik, R., Perkins, M., Aziz, M.A. and Pai, M. (2006) Fluorescence versus Conventional Sputum Smear Microscopy for Tuberculosis: A Systematic Review. The Lancet Infectious Diseases, 6, 570-581. https://doi.org/10.1016/S1473-3099(06)70578-3

[10] Epidemiological Research Methods. Sensitivity, Specificity, Positive Predictive Value, and Negative Predictive Value. The Pennsylvania State University. 2017. https://onlinecourses.science.psu.edu/stat507/node/71

[11] Kivihya-Ndugga, L., van Cleeff, M., Juma, E., Kimwomi, J., Githui, W., Oskam, L., Schuitema, A., van Soolingen, D., Nganga, L., Kibuga, D. and Odhiambo, J. (2004) Comparison of PCR with the Routine Procedure for Diagnosis of Tuberculosis in a Population with High Prevalences of Tuberculosis and Human Immunodeficiency Virus. Journal of Clinical Microbiology, 42, 1012-1015. https://doi.org/10.1128/JCM.42.3.1012-1015.2004

[12] Krishnaswamy, H. and Job, C.K. (1974) The Role of Ziehl Neelson and Fluorescent Stains in Tissue Sections in the Diagnosis of Tuberculosis. The Indian Journal of Tuberculosis, 21, 18-21.

[13] Reid, J.D. and Wolinsky, E. (1969) Histopathology of Lymphadenitis Caused by Atypical Mycobacteria 1, 2. American Review of Respiratory Disease, 99, 8-12. http://www.atsjournals.org/doi/pdf/10.1164/arrd.1969.99.1.8

[14] Krishnaswami, H., Koshi, G., Kulkarni, K.G. and Job, C.K. (1972) Tuberculous Lymphadenitis in South India-A Histopathological and Bacteriological Study. Tubercle, 53, 215-220. https://doi.org/10.1016/0041-3879(72)90019-0

[15] Greenwood, N. and Fox, H. (1973) A Comparison of Methods for Staining Tubercle Bacilli in Histological Sections. Journal of Clinical Pathology, 26, 253-257. https://doi.org/10.1136/jcp.26.4.253

[16] Eshete, A., Zeyinudin, A., Ali, S., Abera, S. and Mohammed, M. (2011) M. tuberculosis in Lymph Node Biopsy Paraffin-Embedded Sections. Tuberculosis Research and Treatment, 2011, 127817.

[17] Rasool, G., Ali, U., Ali, F., Naseem, N. and Nagi, A.H. (2017) Identification of Acid Fast Bacilli in Granulomatous Lymph Node Tissue Biopsy. Gomal Journal of Medical Sciences, 14, No. 4. 
Submit or recommend next manuscript to SCIRP and we will provide best service for you:

Accepting pre-submission inquiries through Email, Facebook, LinkedIn, Twitter, etc. A wide selection of journals (inclusive of 9 subjects, more than 200 journals)

Providing 24-hour high-quality service

User-friendly online submission system

Fair and swift peer-review system

Efficient typesetting and proofreading procedure

Display of the result of downloads and visits, as well as the number of cited articles Maximum dissemination of your research work

Submit your manuscript at: http://papersubmission.scirp.org/

Or contact 迆@scirp.org 